\title{
Oficina de inclusão digital para a construção social: estudo de caso no CEET Vasco Coutinho - Espírito Santo
}

\author{
Workshop digital inclusion on social construction: study case in CEET Vasco Coutinho - Espírito \\ Santo
}

Washington Romão dos Santos

Instituto Federal do Espírito Santo (IFES)

CEP 29.056-255 - Vitória - ES - Brasil

washington_romao@hotmail.com

\author{
Jadson Rafalski \\ Universidade Federal do Espírito Santo (UFES) \\ CEP 29.075-090 - Vitória - ES - Brasil \\ jrafalski@hotmail.com
}

\begin{abstract}
Resumo $O$ estudo tem como objetivo apresentar a relação entre o trabalho desenvolvido na oficina de inclusão digital com a melhoria do desempenho e construção social dos alunos de cursos técnicos do CEET Vasco Coutinho - Estado do Espírito Santo. Através de questionários e entrevistas com os alunos participantes da oficina, buscou-se, inicialmente, entender o nível de conhecimento de informática dos alunos; posteriormente, os dados foram relacionados com o conhecimento e habilidades adquiridas ao término da oficina de inclusão digital. Os dados coletados foram usados para avaliar quanto a oficina contribuiu na apropriação de conhecimentos de informática e na melhoria do desempenho dos alunos no curso técnico, por meio da aplicação dos conhecimentos adquiridos. A pesquisa indica que a oficina de inclusão digital teve um efeito positivo na elevação do nível dos conhecimentos de informática dos alunos participantes da oficina, permitindo utilizar novas ferramentas computacionais, além de promover maior autonomia nos estudos e atividades relacionadas ao dia a dia dos entrevistados.
\end{abstract}

Palavras-Chave: Novas tecnologias, Oficina, Inclusão digital, Construção Social, Informática.

The study aims to present the relationship between the work on digital inclusion workshop with improved performance and social construction of students in technical courses CEET Vasco Coutinho - State of Espirito Santo. Through questionnaires and interviews with the students participating in the workshop, we sought to first understand the level of computer literacy of students; later, the data were related to knowledge and skills acquired at the end of the digital inclusion workshop. The data collected were used to assess how the workshop helped the appropriation of computer skills and improving performance of students in technical course, through application of knowledge learned. Research indicates that the workshop digital inclusion had a positive effect on raising the level of computer skills of students participating in the workshop, allowing use new computational tools, promoting greater autonomy and in studies related to the day to day activities of the respondents.

Keywords: New technologies, Workshop, Digital inclusion, Social Construction, Informatics. 


\section{Introdução}

O cenário da exclusão digital pode ser constatado pelos dados do Instituto Brasileiro de Geografia e Estatística (IBGE) de 2011[1], segundo os quais cerca de 166,9 milhões $(84,9 \%)$ de brasileiros não têm acesso ou nunca tiveram acesso a computador com internet. Apenas $31 \%$ dos 52,8 milhões de domicílios brasileiros possuíam, em 2011, energia elétrica, computador com acesso à internet, aparelho de DVD, TV em cores e máquina de lavar, simultaneamente, conforme o IBGE. Dos 69\% de lares que não tinham todos esses bens ao mesmo tempo, em $84,9 \%$ dos casos, o relato foi de que a ausência era a do computador com acesso à internet. O dado, diz o IBGE, mostra o quanto o país ainda precisa avançar em inclusão digital.

Há cerca de 25 anos, saber ler, interpretar textos e efetuar cálculos matemáticos simples era obrigatório para se viver em harmonia e bem-estar na sociedade e no setor empresarial [2], mas a sociedade contemporânea passa por mudanças causadas pelos grandes avanços tecnológicos e pela globalização, que trouxeram consigo a necessidade constante de qualificação profissional e acadêmica. Nesse contexto, não podemos ignorar que o domínio das novas tecnologias é condição necessária para se manter no mercado de trabalho e que, por conta disso, os conhecimentos em informática podem ser considerados básicos a qualquer atividade profissional na atualidade.

Saber utilizar aplicativos computacionais, como planilhas eletrônicas e editores de texto, é importante tanto para atividades relacionadas ao trabalho quanto para atividades acadêmicas e exige habilidades e competências que o aluno nem sempre domina [3] e [4]. O desconhecimento no uso dos programas comuns, por exemplo, editor de texto, planilha eletrônica, editor de vídeo e áudio, programas para gerenciamento empresarial, entre outros, tem relação com questões diversas, que vão desde a não oferta por parte da escola, até a impossibilidade financeira de realizar o curso específico em uma instituição privada.

Os alunos que frequentam os cursos técnicos em escolas da rede pública são pessoas, geralmente, provenientes de classes menos favorecidas que receberam uma educação escolar e familiar nem sempre adequada às necessidades de mercado de trabalho. Além disso, a faixa etária desse público, que muitas vezes é composto por indivíduos que tiveram que abandonar a escola para trabalhar e que agora, com idade mais avançada, e graças às oportunidades de projetos educacionais como a EJA, têm chance de se qualificar. Esses fatores criam um cenário que dificulta a inclusão digital e social desses sujeitos, evidenciando uma barreira ao aprendizado e apropriação dos conhecimentos disponíveis na rede.
As ferramentas computacionais e os conhecimentos em informática são úteis em todos os ambientes profissionais, facilitando a comunicação e circulação de informações que mudaram a forma como as pessoas percebem e interagem com o mundo, uma vez que [5], a era em que vivemos é a do ciberespaço (espaço virtual para a comunicação utilizando tecnologia), no qual as informações circulam na velocidade das redes de comunicação, interligando pessoas, culturas e conhecimentos.

$\mathrm{Na}$ educação, as ferramentas computacionais proporcionam uma série de vantagens, como aulas mais interessantes por meio dos recursos digitais, pesquisas mais eficientes, chats e web conferências, que tornam possível o contato com diferentes experiências. Devem-se empregar todos os recursos disponíveis para melhorar a qualidade da educação [6], entretanto o aluno precisa conhecer as ferramentas para interagir adequadamente, aproveitando tudo que a tecnologia pode oferecer.

A inclusão digital vai além de ensinar o que é um computador, como ligá-lo ou desligá-lo; ela deve ser pensada como uma forma de incluir efetivamente o sujeito no mundo digital, disponibilizando ferramentas que permitam interpretar os símbolos usados na sociedade digital, bem como toda a lógica que compõe a utilização das ferramentas [7] e [8]. Não significa criar um mero repetidor de comandos, mas um sujeito instruído e capaz de usar conscientemente as ferramentas tecnológicas disponíveis em favor do seu autodesenvolvimento. Ou seja, visa disponibilizar os meios para que as pessoas tenham condições, em uma sociedade digital, de entender, usar as ferramentas existentes e exercer sua cidadania.

Nesse contexto, a proposta da inclusão digital surgiu para atender aquelas pessoas que tinham dificuldade de usar o computador ou não usavam por receio de interagir com o equipamento. Essa situação, considerando a sociedade atual, gera uma série de limitações no dia a dia, uma vez que tudo tem relação com a tecnologia.

Esta pesquisa tem por objetivo contribuir para a compreensão dos benefícios que a oficina de inclusão digital pode proporcionar aos alunos ingressantes nos cursos técnicos do Centro de Estadual de Educação Técnica Vasco Coutinho. Através de dados coletados por questionários, entrevistas e relatos de percepções dos alunos, pretende-se analisar os impactos na vida pessoal e acadêmica dos alunos atendidos com a oficina de inclusão digital. Assim, com essa pesquisa espera-se entender como a oficina de inclusão digital pode gerar benefícios aos estudantes, respondendo ao seguinte questionamento: como a oficina de inclusão digital pode atuar na melhoria efetiva dos conhecimentos de informática, oportunizando 
o desenvolvimento de competências que permitam aos sujeitos a autonomia em relação à busca e compreensão das informações disponíveis na rede e a possibilidade de participação nas discussões políticas, que são cada vez mais feitas em espaços online?

\section{Tecnologias de informação e comu- nicação (TIC's)}

Na última década, os avanços tecnológicos no campo das tecnologias da informação e comunicação (TICs) vêm provocando transformações profundas na forma como as empresas se relacionam com seus mercados e no comportamento de compra dos consumidores. A difusão acelerada da tecnologia da informação, iniciada nos anos 70 com o desenvolvimento da microeletrônica, ganhou novas configurações no século XXI, por meio dos avanços em pesquisas e adição de novos conhecimentos, convergindo em um novo paradigma tecnológico [9]. A forma de trabalho precisou acompanhar esse processo, através de cursos de atualização, principalmente ligados à informática, com a introdução dessa tecnologia no dia a dia das pessoas, tornando uma necessidade como saber ler e escrever, ou seja, a alfabetização digital [2, 4].

Na vida cotidiana, é cada vez maior o número de pessoas atingidas pelas novas tecnologias, por novos hábitos de consumo e indução de novas necessidades. Pouco a pouco, a população vai precisando se habituar a digitar teclas, ler mensagens no monitor, no tablet ou smartphone e entender instruções eletrônicas. Cresce o poder dos meios de comunicação, especialmente a internet, que passa a exercer um domínio cada vez mais forte sobre as crianças e jovens, interferindo nos valores e atitudes, no desenvolvimento de habilidades sensoriais e cognitivas e no provimento de informação mais rápida e eficiente [10].

Considerando que a sociedade vive na era da informação, dominar os meios de acesso à informação significa a inserção como cidadão participante dessa sociedade [11]. O acesso à tecnologia e ao que se convenciona chamar de "alfabetização digital" - que significa entender e utilizar as formas de comunicação, escrita, uso das tecnologias disponíveis nessa nova sociedade pautada no uso do computador e internet - nem sempre é acessível a todos, causando o chamado analfabetismo digital, que é considerado [12] o pior de todos, pois "a alfabetização digital significa habilidade imprescindível para ler a realidade e dela dar minimamente conta, para ganhar a vida e, acima de tudo, ser alguma coisa na vida".

\section{1 A inclusão digital}

As sociedades atuais são da informação, nas quais o desenvolvimento das tecnologias cria um ambiente cultu- ral e educativo suscetível para diversificar as fontes do conhecimento e do saber. Essa diversificação advém do acesso à internet e das novas ferramentas computacionais, e a inclusão digital entre em cena como uma proposta de inserção daquelas pessoas que não tiveram acesso ao mundo digital [13].

As novas tecnologias de comunicação e informação (TIC's) trouxeram mudanças consideráveis e positivas para a educação. [...], no entanto, elas precisam ser compreendidas e incorporadas pedagogicamente, tanto pelos professores, quanto pelos alunos. Isso significa que é preciso respeitar as especificidades do ensino e da própria tecnologia para garantir que o seu uso realmente faça diferença. Não basta usar o computador, é preciso utilizar de forma que a ferramenta oportunize a construção do conhecimento, ou seja, forma pedagogicamente correta [14].

Como a inclusão digital vai além de ensinar o que é um computador, é preciso instruir os sujeitos a usar conscientemente as ferramentas tecnológicas disponíveis, mostrando os benefícios, sem, contudo torna-lo alienado. De acordo com Cruz (2004), para um indivíduo ser considerado incluído digitalmente, é preciso que o mesmo esteja preparado para utilizar as máquinas de forma a extrair o máximo de benefícios, isto é, usufruir de seus recursos de maneira plena. Esse pensamento é semelhante [15] e [16] quando dizem entender que a "[...] inclusão deve possibilitar que cada ser possa descobrir a sua autoimagem, levando-o a acreditar em si próprio e mostrando para outros do que é capaz".

Estar incluído na sociedade é condição vital para o desenvolvimento de qualquer cidadão, dessa forma, a inclusão digital tem a função de criar alternativas para inserir os sujeitos nessa nova sociedade da informação, através do uso de ferramentas computacionais de acesso e produção da informação [17]. É preciso ter em vista as complexas relações de poder na sociedade, que dificultam processos de inclusão digital para amplas parcelas da população [18]. Portanto, a escola pode oportunizar, através de projetos específicos, a alfabetização digital. Pois, as expectativas de melhoria da qualidade de vida acompanham a chegada do acesso às tecnologias digitais, que surgem em função do uso da informação, da melhoria da educação ou da criação de oportunidades para empreender [19].

Em função da crescente virtualização do trabalho e dos avanços propiciados pelas novas tecnologias, existe uma relação entre a exclusão digital e a exclusão social [20]. Aqueles que são colocados à margem nesta sociedade capitalista e excludente terão menos oportunidades de acesso às TICs e a internet, configurando um estado de exclusão digital e social [20] e [21]. 
Além das relações de inclusão e exclusão, a falta de conhecimento prévio em determinadas áreas deve ser considerada, pois ela faz com que o aluno, mesmo participando de propostas inclusivas oferecidas pela escola pública, sinta-se excluído e, por consequência, desestimulado a aprender, o que pode causar menor rendimento no curso e/ou abandono do mesmo. Em outros casos, embora os alunos consigam seus certificados, muitas vezes terão que declinar às ofertas do mercado por não estarem ainda aptos a exercer funções, gerando prejuízo social.

\subsection{Construção social por meio da inclusão digital}

Incluir digitalmente as pessoas não significa apenas oferecer um computador e ensinar como usá-lo; é preciso entender o contexto social em que vivem e fornecer instrumentos de mudança. Diversos autores [22], [23] e [7] acreditam que a inclusão digital é resultado de uma junção coordenada de fatores, tais como renda, educação e tecnologias de informação e comunicação, sendo que os dois primeiros fatores atuam diretamente na inclusão social das pessoas na sociedade e, por consequência, impactam a inclusão digital, criando uma relação mutuamente influenciada.

A inclusão social tornou-se palavra fácil, cujas práticas tendem a ser o reverso, e cita o exemplo da progressão automática na educação, na qual o aluno, independentemente de seu desempenho, consegue concluir o ensino médio. [11]. Dentre as definições de inclusão social, existem autores mais críticos sobre o processo e outros com uma ótica mais otimista a respeito inclusão social das pessoas. Entretanto, todos concordam que é um problema que deve ser combatido, sobretudo nos países de regime democrático.

A inclusão social pode ser entendida como a ação de proporcionar para populações que são social e economicamente excluídas oportunidades e condições de serem incorporadas à parcela da sociedade que pode usufruir de bens e/ou serviços [23] e [25]. Em um sentido mais amplo, a inclusão social envolve também o estabelecimento de condições para que todos os habitantes de um país possam viver com qualidade de vida, interagindo em sociedade e tendo acesso a bens e serviços que permitam atuar como cidadãos plenos, dotados de conhecimentos, meios e mecanismos de participação política que os capacitem a agir de forma fundamentada e consciente.

Nesse sentido, a inclusão digital pode ser compreendida como uma ferramenta para promover a inclusão social, uma vez que proporciona às pessoas acesso à informação, através das ferramentas computacionais.
A inclusão digital tem relação com as condições sociais da população; logo, representa um desafio sociológico - que perpassa a relação de ser mera relação de dados, informação e conhecimento - afirma que a informação é uma matéria-prima que o conhecimento deve dominar e integrar [25] e [26]. O processo de inclusão digital ganhou força com a popularização dos meios digitais e acesso cada vez maior de pessoas trocando informações em rede, disseminando conteúdos, gerando novos materiais e novos conhecimentos. As mídias digitais, nos seus mais diversos formatos, permitiram que um movimento de inclusão pudesse ser construído e disseminado.

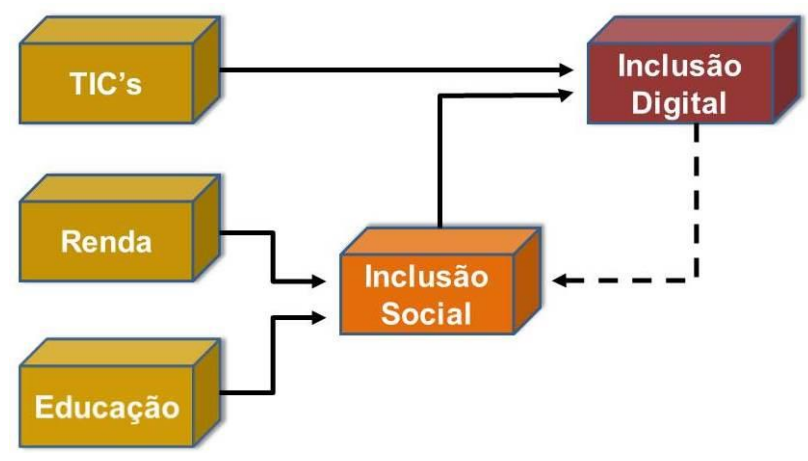

Figura 1: Inclusão social para construir inclusão digital [22]

Através de relações descentralizadas e verticalizadas entre produtores e consumidores de informação e conhecimento, as mídias digitais possibilitaram que ambos possam permutar suas funções e papéis sociais, ora como produtores, ora como consumidores dos processos de conteúdos que circulam na mídia digital [27] e [28].

Para proporcionar o acesso significativo às novas tecnologias, ao conteúdo, à língua, ao letramento, à educação, as estruturas comunitárias e institucionais devem ser levados em consideração [4]. Dessa forma, fica evidente que a inclusão digital não se resolve comprando computadores para a população de baixa renda e ensinando como utilizar um ou outro aplicativo.

Ter acesso à infraestrutura tecnológica é apenas um dos fatores relacionados com a inclusão/exclusão digital, não sendo o único, nem o mais relevante [18] e [28]. A questão inclusão digital envolve mais fatores além da infraestrutura de acesso, como conhecimento para utilizar a informação, alfabetização digital para entender os termos utilizados, acesso à internet e conhecimentos para utilizar adequadamente tudo que a tecnologia possa oferecer.

Considerando as diversas questões que envolvem a inclusão digital e a emancipação dos sujeitos, é imprescindível que o letramento digital seja introduzido na vida de todos, por representar um dos fatores de inserção dos sujeitos na sociedade [12] e [27]. Além disso, o letra- 
mento oportuniza o acesso a novas formas de ensinar e aprender, além de situar cada indivíduo na sociedade da informação. Ou seja, representa uma "janela de oportunidades" para o mundo.

\section{A oficina de inclusão digital}

Entendendo que a inclusão digital deve ser pensada como uma forma de incluir efetivamente os sujeitos no mundo digital, disponibilizando ferramentas que permitam interpretar os símbolos usados na sociedade digital, foi proposta uma oficina de inclusão digital aos alunos dos cursos técnicos subsequentes do CEET Vasco Coutinho, com objetivou disponibilizar os meios para que os alunos com dificuldades e deficiências em conhecimentos de informática tivessem condições de entender e usar as ferramentas existentes, oportunizando o exercício da cidadania.

Com essa proposta, os alunos do curso de licenciatura em informática do CEAD-IFES ofertaram 20 vagas para ensinar conceitos básicos de informática, uma oficina de inclusão digital, de forma que as pessoas que tinham mais dificuldades em usar o computador pudessem ter mais autonomia no seu dia a dia com as ferramentas computacionais. Foi cedido pela instituição CEET Vasco Coutinho um dos laboratórios de informática para oferecer o curso e as aulas foram então ministradas no período noturno antes do início das disciplinas regulares, justamente pra possibilitar a presença dos alunos na oficina. Os laboratórios estavam equipados com o número suficiente de computadores e demais infraestruturas para perfeita condução do curso.

O objetivo da oficina de inclusão digital era atender uma diversidade de alunos, todos com algum nível de dificuldade em usar o computador e suas funcionalidades, portanto foram utilizados critérios como o grau de dificuldade que cada aluno possuía em usar o computador, bem como as limitações relacionadas em usar a internet, para direcionar as aulas e atender os objetivos propostos pelo curso.

A oficina de inclusão digital não foi planejada como um curso básico de informática em que os alunos aprendem a usar programas de edição de documentos, planilhas eletrônicas, vídeos etc. O intuito do curso foi oportunizar o desenvolvimento de competências que permitam aos sujeitos a autonomia em relação à busca e compreensão das informações disponíveis na rede e a possibilidade de participação nas discussões políticas, que são cada vez mais feitas em espaços online. Para conhecimentos mais técnicos, os alunos deverão buscar cursos específicos na área.

A oficina de inclusão digital apresenta uma forte contribuição tecnológica e social, articulando técnicas já disponíveis e disseminadas com prática - isso é um ponto positivo e relevante, pois aumenta a eficiência e alcance dos objetivos propostos. O projeto poderá trazer impactos positivos imediatos ao público-alvo, possibilitando o ingresso social desses sujeitos e melhora significativa de qualidade de vida.

\subsection{Os conteúdos ministrados}

No decorrer do curso os alunos desenvolveram diversas atividades, iniciando com a descoberta do computador, seus componentes, a função de cada parte e o auxílio das teclas de atalho. Posteriormente desenvolveram:

- Digitação e formatação de documentos;

- Edição de documentos no editor de texto;

- Inserção de tabelas no editor de texto;

- Criação de apresentação no Power point;

- Criação de uma conta de $e$-mail;

- Criação de uma planilha para controle de gastos.

As atividades foram sugeridas com base nas necessidades dos próprios alunos, através de uma coleta de informações com alunos e professores da instituição. Dessa forma, os conteúdos ministrados foram pensados para o nível de dificuldade da turma, contextualizando com os interesses e necessidades de cada um.

Foi adotada uma sequencia de conteúdos que privilegiasse o aprendizado dos alunos, aliando a utilidade de cada aplicativo no dia a dia dos estudantes, bem como o desenvolvimento da autonomia. Apesar de o curso ser introdutório, ele foi pensado e executado para oferecer o ferramental necessário para os alunos pudessem utilizar o conhecimento adquirido e agregar novos conhecimentos obtidos com a prática e/ou outros cursos específicos.

\section{Caracterização da amostra}

A pesquisa foi realizada com 20 alunos que participaram da oficina de inclusão digital no período de julho a dezembro de 2013. Analisando o perfil dos estudantes atendidos pela oficina de inclusão digital, é possível notar que $75 \%$ estão compreendidos na faixa etária dos sujeitos que têm mais de 40 anos de idade, além disso, são em sua maioria mulheres, conforme pode ser observado no Gráfico 1 e 2 . Assim é possível perceber que se trata de pessoas que não tiveram oportunidade de estudar no tempo certo e/ou buscam um curso técnico para se qualificar, ou seja, estão dispostos a aproveitar as oportunidades oferecidas pelo Estado. 


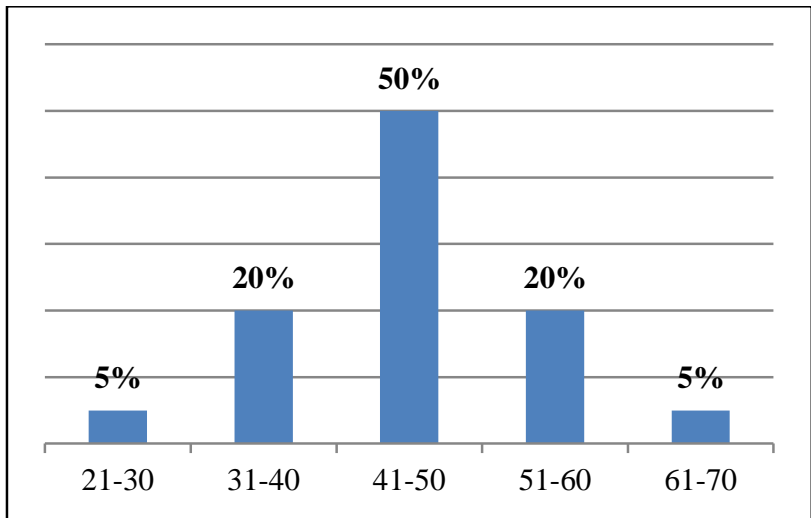

Gráfico 1: Caracterização da amostra por faixa etária

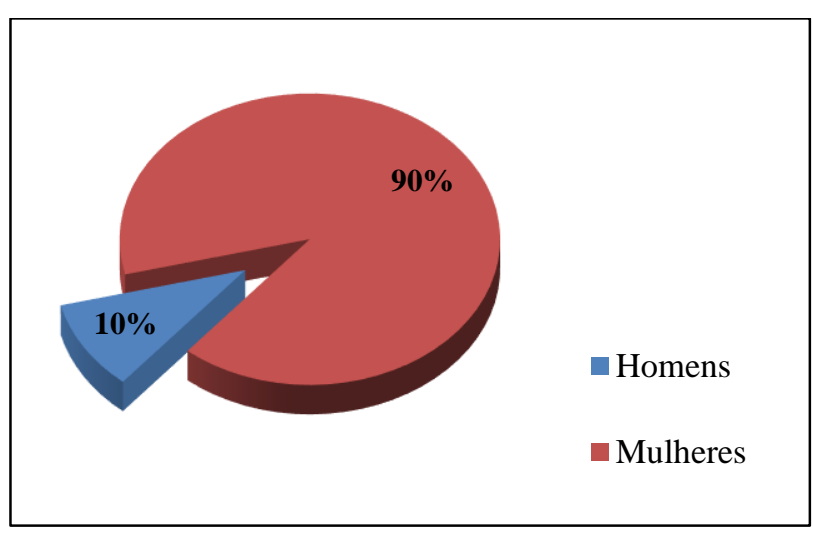

Gráfico 2: Idade e sexo

Os alunos são provenientes dos diversos cursos técnicos que o CEET Vasco Coutinho oferece, majoritariamente frequentam o curso técnico em modelagem do vestuário, de acordo com o Gráfico 3. Um dos motivos levantados está no fato de não existir uma disciplina de introdução à informática no curso de modelagem, mesmo sendo necessário utilizar o computador em disciplinas como desenho técnico e produção de moda. Geralmente, tais alunos possuem algum tipo de rendimento, trabalho ou ajudam nas despesas domésticas com alguma atividade com ou sem carteira assinada.

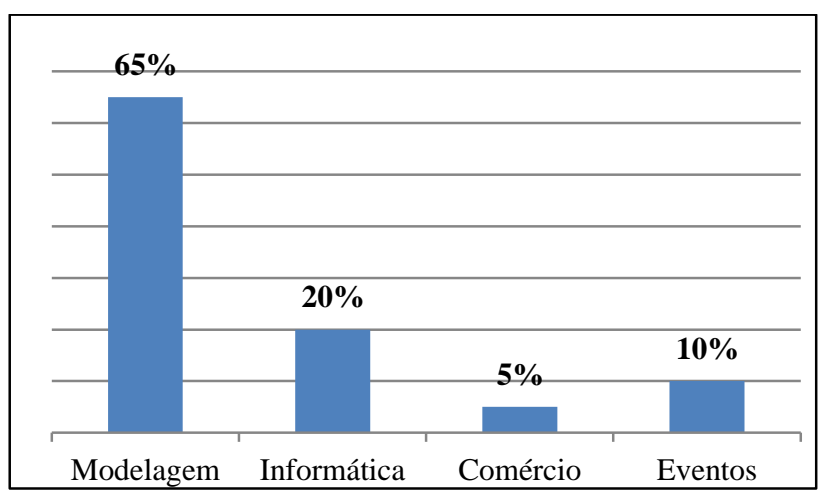

Gráfico 3: Curso que frequenta
Sobre o acesso a computador, a maioria dos sujeitos envolvidos possui acesso fácil ao equipamento, tendo-o em casa, na escola ou no trabalho. Foi-lhes perguntado a respeito de quanto tempo utilizam o computador, e a maioria começou a utilizar há menos de um ano, conforme exposto no Gráfico 4. Isso explica, em parte, a dificuldade e pouca familiaridade com o uso das ferramentas computacionais.

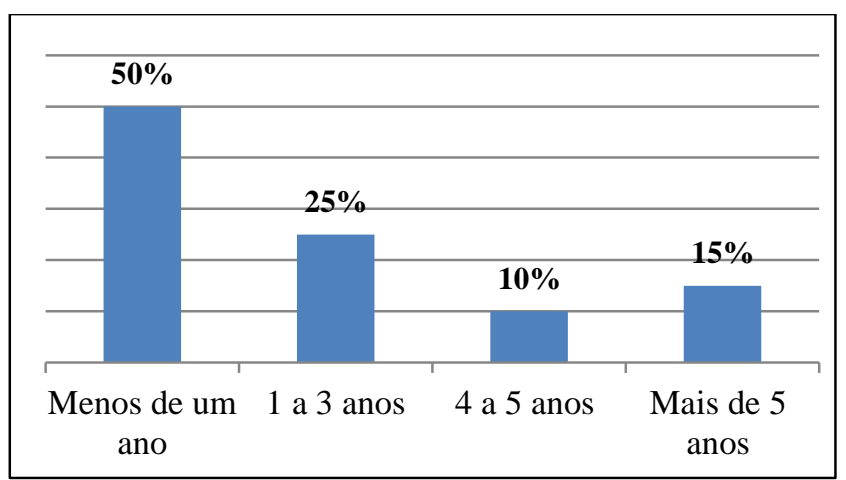

Gráfico 4: Tempo que utiliza o computador

Alguns dos alunos utilizam computadores no trabalho e escola, mas a maior parte dos entrevistados tem esse aparelho em casa e, nesse caso, os acessos são feitos na própria residência, como pode ser notado através do Gráfico 5. São pessoas que, em sua maioria, estão voltando a estudar e enxergam nos cursos técnicos uma oportunidade de qualificação.

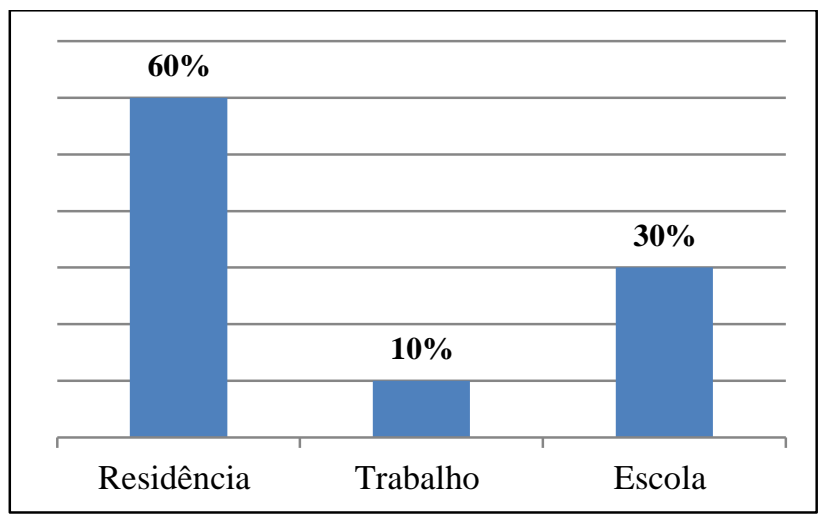

Gráfico 5: Locais onde acessa o computador

A necessidade de usar o computador levou os alunos a frequentar a oficina de inclusão digital, para obter o conhecimento necessário que permitisse realizar, com mais segurança, atividades corriqueiras como usar a internet, realizar pesquisas, enviar emails e fazer trabalhos escolares.

A seguir são apresentados as análises dos dados da pesquisa sobre a evolução dos alunos no decorrer da oficina de inclusão digital, relacionando dados do início do curso com o final, além de fundamentar com os relatos dos próprios alunos a dispeitos do seu aprendizado. 


\section{Análise e resultados da pesquisa}

Através do questionário foi possível notar que grande parte dos respondentes tem muitas dificuldades em realizar atividades básicas com o computador, essas geram limitações sérias no dia a dia dos sujeitos entrevistados. Para analisar a percepção sobre ações simples relativas à utilização do computador, foi aplicado um questionário antes da realização da oficina de inclusão digital e outro ao término da mesma, de forma que fosse possível relacionar os resultados.

Ao analisar a diferença das respostas obtidas a respeito de ligar e desligar o computador com segurança podese constatar que depois da oficina os alunos apresentaram uma significativa melhora, passando a entender, na sua maioria, qual a forma correta de realizar o procedimento, como pôde ser observado no Gráfico 6.
O Gráfico 7 mostra os dados comparados referentes a redação e formatação de textos no computador, e através dele pode-se verificar uma evolução significativa dos alunos nesse quesito. Antes da oficina, cerca de $80 \%$ dos alunos disseram que realizavam a atividade com muita dificuldade ou alguma dificuldade, representando uma séria limitação que os impedia de fazer uma carta simples, por exemplo. Após a oficina, os alunos demonstraram mais seguraça em executar a atividade e cerca de $75 \%$ afirmaram que apresentavam pouca ou quase nenhuma dificuldade em executar essa dificuldade. Outro aspecto é o número de sujeitos que afirmou digitar e formatar com pouco ou quase nenhuma dificuldade, antes eram $15 \%$ e depois da oficina esse número passou para $50 \%$ dos entrevistados. Isso demonstra o importância que o oficina representou aos participantes.

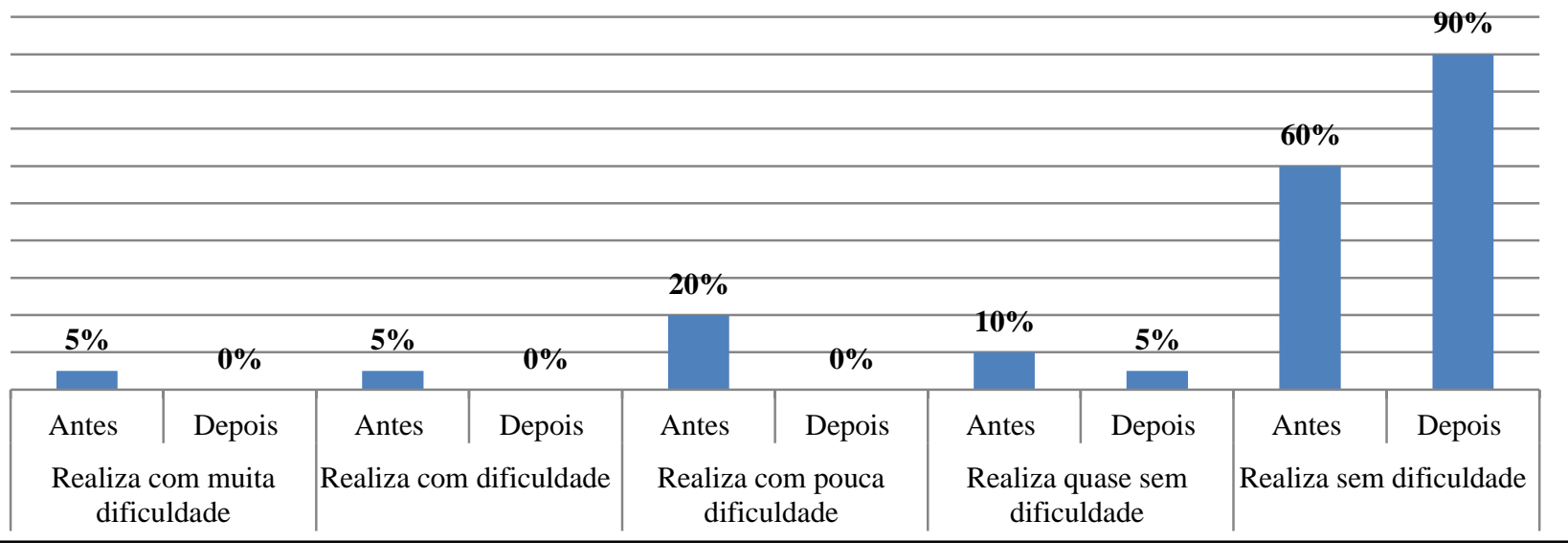

Gráfico 6: Comparando a percepção sobre ligar e desligar o computador

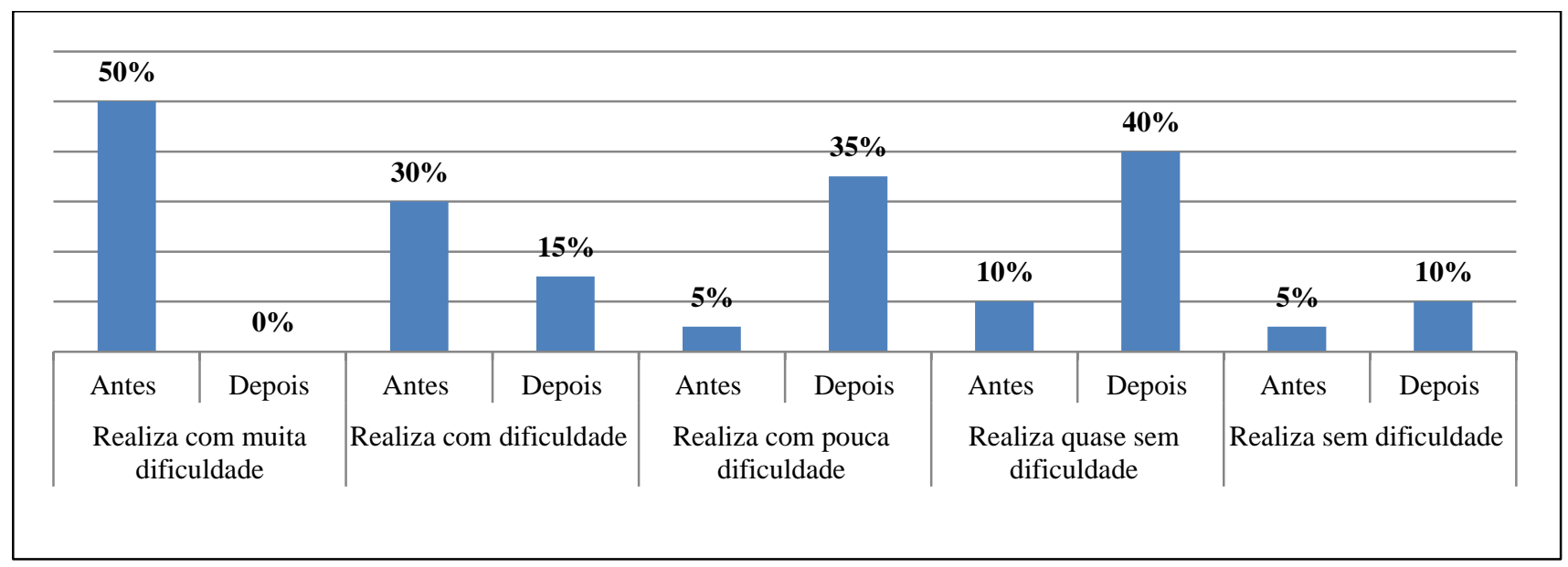

Gráfico 7: Comparando a percepção sobre redação e formatação de textos 
Os alunos demonstraram-se satisfeitos em poder realizar, com relativa facilidade, atividades em que antes tinham extrema dificuldade ou não conseguiam realizar. $\mathrm{O}$ fato de aprender a lógica de funcionamento do programa e noções simples de digitação e formatação permitiu aos alunos maior autonomia em redigir trabalhos, e-mails e documentos.

Quando analizados os dados sobre percepção de gerenciamento de arquivos, cujos dados estão disponíveis no Gráfico 8, os alunos demonstram uma evolução significativa no entendimento dos conceitos de armazenamento, embora sejam abstratos, parecem ter entendido a lógica de organização e armazenamento dos arquivos no computador e discos removíveis. Antes da oficina, cerca de $75 \%$ dos entrevistados afirmavam ter dificuldade ou muita dificudade em gerenciar os documentos e recursos de arquivos, ou seja, não entendiam onde os arquivos ficavam armazenados, como salvar adequadamente e depois encontrar o documento salvo. Depois da oficina, cerca de $70 \%$ dos alunos relataram ter pouca ou quase nenhuma dificuldade em gerenciar os documentos e arquivos armazenados no computador ou em mídias removíveis.

A internet é uma fonte importante de pesquisa para todas as atividades, sejam elas profissionais ou acadêmicas. Ter acesso e saber utilizar os recursos que a rede mundial de computadores oferece representa autonomia e inserção no mundo de conhecimento. No Gráfico 9, é possivel verificar a evolução quanto a percepção dos alunos quanto à utilização dos mecanismos de busca na internet.

Pode-se constatar que pelo menos $40 \%$ relataram que usavam a internet com dificuldade ou muita dificuldade. Esse número foi alterado após a oficina, passando representar apenas $20 \%$ das respostas. Em contrapartida, o número de pessoas que relataram ter pouca dificuldade e não dificuldade saltou de $35 \%$ para $55 \%$. Isso demonstra o impacto positivo que oficina de inclusão digital gerou na vida nos sujeitos, passaram a ter mais autonomia nas atividades diárias.

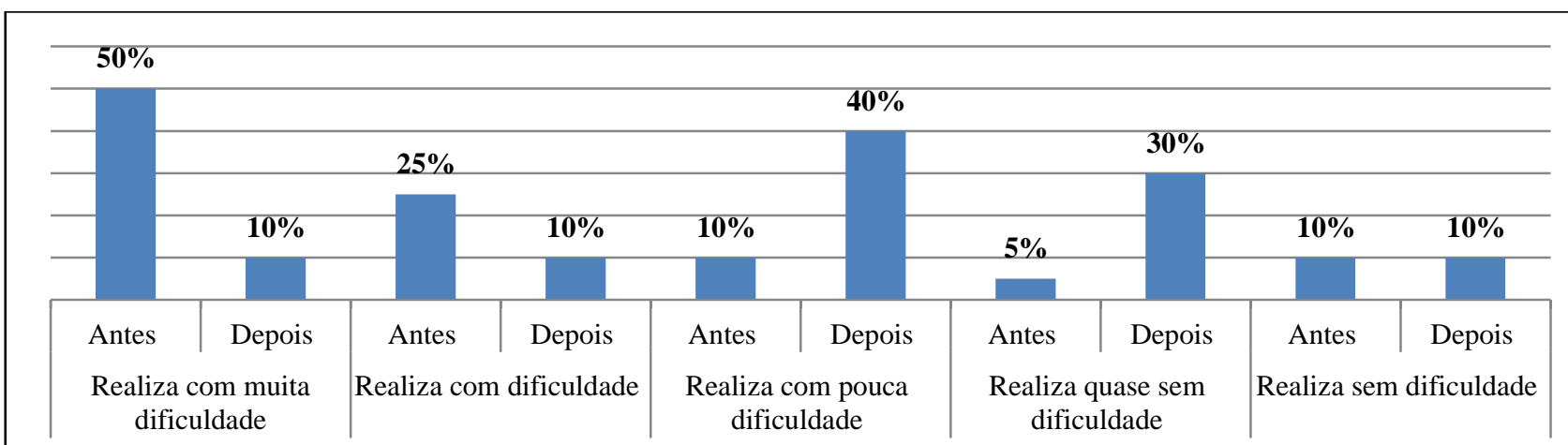

Gráfico 8: Comparando a percepção de gerenciamento de arquivos

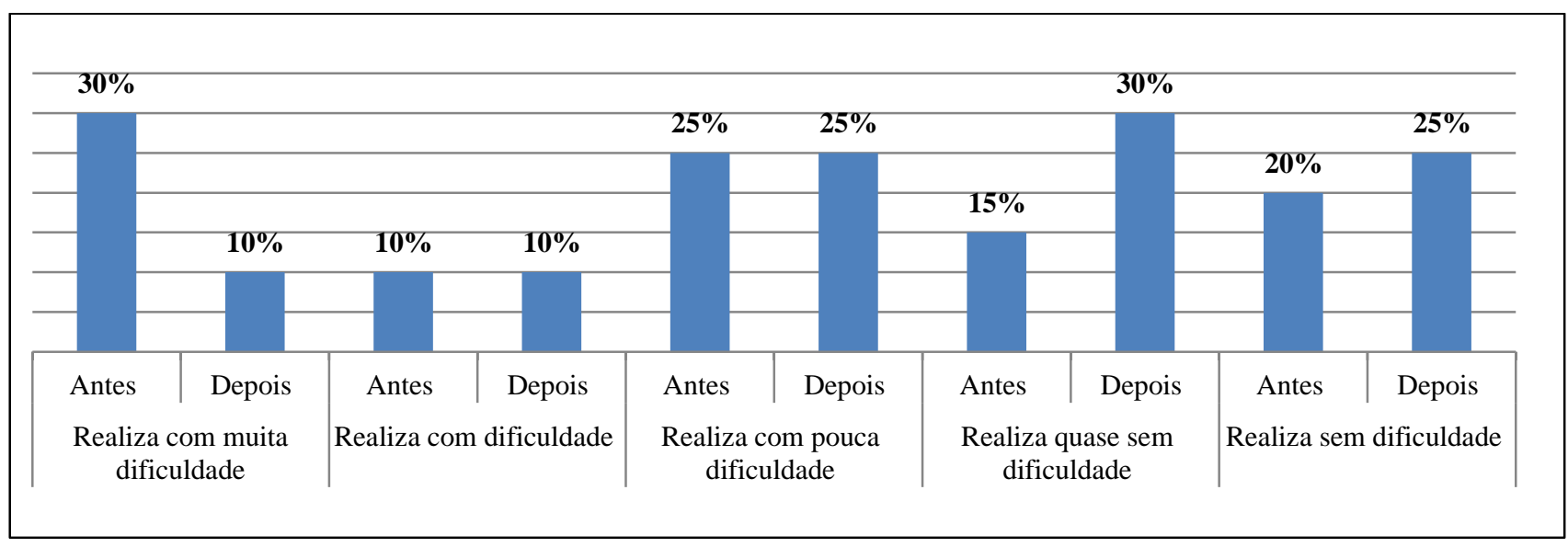

Gráfico 9: Comparando a percepção de como utilizar mecanismos de pesquisa na internet 
Adicionalmente foram realizadas entrevistas com os alunos para entender de forma mais aprofundada o efeito da oficina na vida delas. Os alunos relatam mais motivação em continuar o curso técnico que estavam cursando na instituição, bem como em frequentar um curso regular de informática para se aprofundar conhecimentos introduzidos na oficina.

Para alguns foi uma oportunidade única, pelo fato de ter sido oferecido em um horário acessível e nas dependências do CEET Vasco Coutinho, onde estudavam, permitindo que o frequentassem sem prejudicar os afazeres rotineiros. Além disso, a preocupação com o aprendizado e a característica personalizada do curso foram apontados como pontos positivos.

Outro ponto que deve ser mencionado é o sentimento de capacidade que os alunos passaram a demonstrar, ou seja, antes da oficina estavam apreensivos e, segundo relatos, no decorrer foram perdendo o 'medo', entendendo que eram capazes de realizar as atividades. Com isso, apresentavam uma estima elevada ao final da oficina, por aprender a utilizar recursos que antes eram estranhos ou complexos demais e agora passam a ter outro significado.

Os alunos ainda relataram que quando precisaram utilizar softwares específicos nas disciplinas dos cursos técnicos em que frequentavam, tiveram menor dificuldade e puderam aprender com mais facilidade o conteúdo ministrado e a usar o programa.

Ao final do curso técnico, os alunos encontrados, relataram que a experiência foi importante para sua formação, permitindo desenvolver com mais autonomia seus trabalhos e atividades com ajuda do computador. Além disso, associaram os conhecimentos obtidos no curso com as oportunidades profissionais obtidas ao final do curso, como uma nova colocação no mercado de trabalho.

\section{Conclusões e pesquisas futuras}

A pessoa excluída digitalmente apresenta uma série de limitações e restrições em uma sociedade cada vez mais digitalizada, e o processo de inclusão digital não termina com o acesso ao computador, pois é preciso que as pessoas saibam usar adequadamente o aparelho e os recursos disponíveis, para atender aos objetivos pessoais e acadêmicos. Para dar conta disso, a oficina de inclusão digital relatada no caso teve o papel de introduzir conhecimentos básicos de informática que significaram melhorias na interação com o mundo digital, com a utilização de recursos básicos que facilitam o dia a dia de todos.

A pesquisa indica que a oficina de inclusão digital teve um efeito positivo na elevação do nível dos conhecimentos de informática dos alunos participantes, bem como na autoestima de cada sujeito atendido. Pelos dados apresentados foi possível visualizar o grau de evolução, compa- rando a percepção pessoal dos alunos antes e depois da realização da oficina. Em questões como ligar e desligar adequadamente, redigir e formatar textos, os alunos que antes apresentavam em sua maioria grande dificuldade, passou a ter pouca ou nenhuma dificuldade em executar a tarefa.

A oficina de inclusão digital demonstrou ter uma influência significativa na vida dos alunos, permitindo que muitos destes apresentassem uma melhoria quanto a conhecimentos básicos de informática. Esse conhecimento, de acordo com os alunos, ajudou a realizar tarefas com o auxílio do computador, que antes não eram possíveis.

O aumento da estima proporcionada pelo sentimento de capacidade repercute em estímulo para permanência profissional e busca de novos conhecimentos. Apesar de a oficina oferecer conhecimentos básicos, que podem ser aprofundados de acordo com o interesse de cada um, eles proporcionam grande autonomia em atividades corriqueiras, como pesquisas na internet, envio e recebimento de emails, elaboração e formatação de trabalhos escolares. Essa autonomia representa uma mudança significativa para os alunos, que agora podem usar sem medo o computador, realizar pesquisas e se apropriar de conhecimentos que antes não lhes eram acessíveis.

Os dados iniciais obtidos através dessa pesquisa apontam para uma diversidade de possibilidades de investigações futuras, podendo ser aplicado procedimentos semelhantes em diferentes cursos de instituições que ofertam cursos técnicos ou mesmo de nível fundamental e médio, buscando verificar a possibilidade generalização dos resultados do estudo.

Adicionalmente, considera-se relevante oferecer e avaliar outros tipos de cursos de formação semelhantes, de forma a oferecer cursos que minimizem as deficiências educacionais dos estudantes, avaliando os resultados de cada iniciativa.

\subsection{Limitações}

Esta pesquisa teve como limitação a amostragem por conveniência, considerada não probabilística, que dificulta a inferência/generalização. Portanto, as conclusões tem validade apenas para a amostra pesquisada, necessitando de mais pesquisas similares para realizar inferências.

\section{Referências}

[1] IBGE - Instituto Brasileiro de Geografia e Estatística. Uma análise das condições de vida da população brasileira 2012. Disponível em: $<$ http://www.ibge.gov.br/home/estatistica/populac a

/condicaodevida/indicadoresminimos/sinteseindic 
sociais2012/default tab pdf.shtm>. Acesso em: 14 fev. 2013.

[2] E. Rondelli. Quatro passos para a inclusão digital. Disponível em: $<\mathrm{http}$ ://www.comunicacao.pro.br/setepontos/5/4p assos.htm >. Acesso em: 20 dez. 2012.

[3] R. Cruz. O que as empresas podem fazer pela inclusão digital. São Paulo:Instituto Ethos, 2004.

[4] M. Warschauer, Tecnologia e inclusão social: a exclusão digital em debate. Trad. Carlos Szlak. São Paulo: SENAC, 2006.

[5] P. Levy. A máquina universo: criação, cognição e cultura informática. Porto Alegre: Artes Médica, 1988.

[6] P. Freire. Pedagogia da autonomia: saberes necessários à prática educativa. 15. ed. São Paulo: Paz e terra, 1990.

[7] D. P. A. Ausubel. Aprendizagem significativa: a teoria de David Ausubel. São Paulo: Moraes, 1982.

[8] J. Piaget, O diálogo com a criança e o desenvolvimento do raciocínio. São Paulo: Scipione, 1997.

[9] M. Castells, A sociedade em rede. São Paulo: Paz e Terra, 1999.

[10] J. C. Libâneo. Perspectivas de uma pedagogia emancipadora face às transformações do mundo contemporâneo. Pensar a Prática, Goiânia, 1(1), 1998.

[11] H. Assman. Reencantar a educação - rumo à sociedade aprendente. 8. ed. Petrópolis: Vozes, 2004.

[12] P. Demo. Inclusão digital - cada vez mais no centro da inclusão social. Inclusão Social, Brasília, v. 1(1), 36-38, out./mar., 2005.

[13] J. Delors. Educação - um tesouro a descobrir. Relatório para a UNESCO da Comissão Internacional sobre Educação para o século XXI. São Paulo: Cortez; Brasília: MEC; UNESCO, 1998.

[14] V. M. Kenski. Educação e tecnologias: o novo ritmo da informação. São Paulo: Papirus, 2007.

[15] N. M. C. Pellanda, Schlünzen, Elisa, T. Schlünzen, S. J. v (Orgs.). Inclusão digital: tecendo redes afetivas/cognitivas. Rio de Janeiro: $D P \& A$, 2005.

[16] M. L. Belloni. Educação a distância. 3. ed. Campinas, São Paulo: Autores Associados, 2003.
[17] R. Martini. Inclusão digital \& inclusão social. Revista Inclusão Social, Brasília, 1(1), 2005. Borges Neto, E. J. R. Santos. O que é inclusão digital? Um novo referencial teórico. Linhas Críticas, 15(29), 345-362, 2009.

[18] M. D. Voelcker, L. C. Fagundes, F. Ribeiro. Facilitando o construtivismo na inclusão digital. Novas Tecnologias na Educação, 9 (2), 1-12, 2011.

[19] S. A. Silveira. Exclusão digital: a miséria na era da informação. São Paulo: Fundação Perseu Abramo, 2001.

[20] I. C. Moreira. A inclusão social e a popularização da ciência e tecnologia no Brasil. Revista Inclusão Social, Brasília, 1 (2), 11-16, 2006.

[21] A. M. Silva Filho. Inclusão Digital: Em Busca do Tempo Perdido. Revista Espaço Acadêmico, 40 (4), 2004.

[22] E. Morin. A religação dos saberes: o desafio do século XXI. Rio de Janeiro: Bertrand Brasil, 2001.

[23] A.V. Cabral Filho, E.D.T. Cabral, Inclusão digital para a inclusão social: perspectiva e paradoxos. Revista Debates, Porto Alegre, 4(1), 11-28, jan.jun. 2010.

[24] M. J. Rodrigues. CVEE - Construção e implementação de uma comunidade virtual de educação especial. Bragança: Escola Superior de Educação de Bragança, 2011. [dissertação de mestrado].

[25] M. H. Bonilla. O Brasil e a alfabetização digital. Jornal da Ciência, Rio de Janeiro, p. 7- 13, abr. 2001. Disponível em: $<$ http://www2.ufba.br/ bonilla/artigojc.htm>. Acesso em: 12 jan. 2013.

[26] P. Freire. O desafio da inclusão digital. Transinformação, 6 (2), 189-194, 2004.

[27] S. A. Silveira. Inclusão digital, software livre e globalização contra-hegemônica. Práticas Estratégicas, 20, 421-446, 2005.

[28] J. S. Souza, M. H. S. Bonilla. Exclusão/inclusão: elementos para uma discussão. Liinc em Revista, 5 (1), 133-146, 2009. 